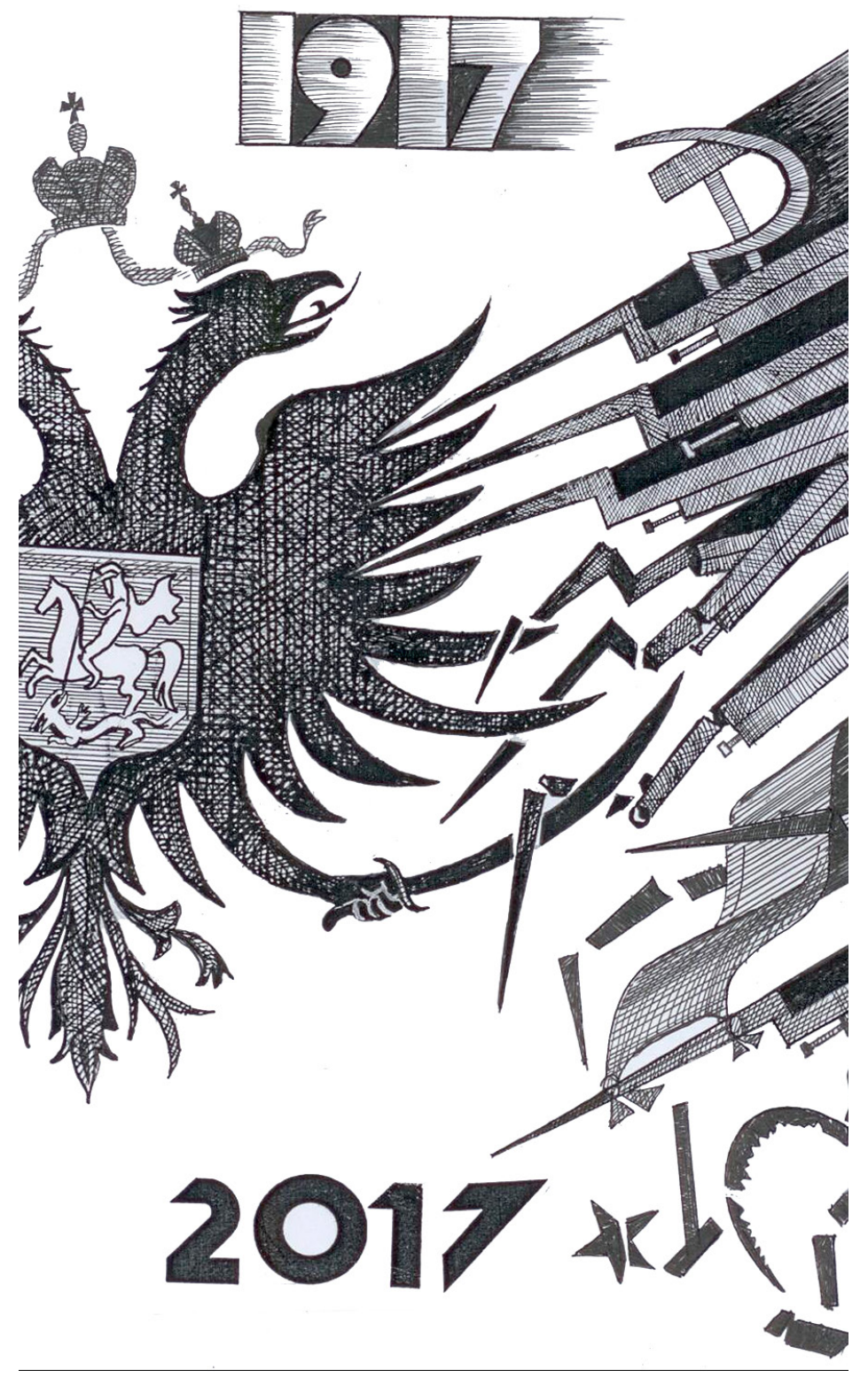

\title{
Россия в XX веке. Цена революции
}

В.И. КлИстоРИн, доктор экономических наук,

Институт экономики и организации промышленного производства СО РАН, Новосибирский государственный университет, Новосибирск.

E-mail: klistorin@ieie.nsc.ru

Рассматриваются экономические и демографические последствия российской революции 1917 г. В краткосрочном периоде они не оказали существенного влияния на макроэкономические показатели страны. Но последующие события - национализация банков и промышленных предприятий, инфраструктуры, Гражданская война и экспорт революции вызвали глубочайший кризис. Милитаризация экономики и массовые репрессии привели к сокращению и снижению качества человеческого капитала. Бурный экономический рост неоднократно сменялся периодами застоя, часто носил восстановительный характер. Проблемы неравенства и снятия барьеров на пути развития производительных сил оказались нерешенными для России в XX веке.

Ключевые слова: революция, национализация, войны, репрессии, неравенство, экономический рост, конкуренция, собственность, доходы

Гражданские войны вызываются людьми, воображающими, что их личное неудовлетворительное положение может быть лучше всего исправлено всеобщей разрухой.

Уильям Петти, врач, экономист и политический деятель XVII в.

Столетие, прошедшее после драматических событий 1917 г., повод для размышлений над результатами и последствиями революций вообще и российской в особенности. На мой взгляд, революция в России была неизбежной. Свидетельства тому предшествовавшие ей попытки реформирования государственного и социального устройства, предпринимавшиеся в начале XX века («революция сверху»), обострение противоречий в условиях войны. Кроме того, что население Российской империи было очень молодо, а молодежь склонна к радикализму, многие народы, населявшие окраины империи, противились русификации и боролись за автономию и независимость. Наконец, в начале XX века российская экономика развивалась достаточно быстро, но плодами экономического роста могли воспользоваться немногие ${ }^{1}$.

Авторские оценки дореволюционного развития России и его изменения в ходе Первой мировой войны изложены в $[1,2]$ 


\section{Накануне}

Россия была страной олигархического капитализма: с засильем монополий, сращиванием власти и богатства, вопиющим социальным и имущественным неравенством. В разных слоях общества были популярны социалистические идеи - от марксизма и анархизма до христианского и прусского социализма. Наконец, слабый император, неспособный контролировать двор и семью, допустивший кадровую чехарду в правительстве и вмешательство странных личностей в решение государственных вопросов, не доверяющий никому и потому постоянно попадающий под чье-то влияние. Все это гарантировало рост популярности радикальных идей и методов борьбы за власть. Сложился общественный консенсус вокруг простой формулы «Так дальше жить нельзя».

Сами по себе революция 1917-го и предшествующие ей события вряд ли могли сравниться по своему влиянию на макроэкономические показатели развития страны с процессами, запущенными в ходе Первой мировой войны. Грабежи и беспорядки, забастовки, демонстрации, митинги и т.П., конечно, повлияли на дезорганизацию экономической жизни, но последующие сознательные действия советского правительства, которые казались вынужденными или выдавались за таковые, привели к экономической катастрофе. На фоне дальнейших событий революция 1917 г. выглядела просто «праздником непослушания».

Прежде всего, следует выделить экономические последствия экспроприации и национализации банков, всей финансовой сферы и промышленных предприятий. В результате денежное обращение было разрушено, заводы останавливались из-за нехватки сырья и полуфабрикатов, шахты были затоплены. Попытки многочисленных советов, не подчинявшихся друг другу, рационализировать материальные потоки приводили к хаосу.

Другим последствием революции стала Гражданская война. В.И. Ленин задолго до революции выдвинул лозунг «превращения войны империалистической в войну гражданскую». Возможно, тогда он и не подозревал, насколько был прав. Без Гражданской войны Советская власть не удержалась бы. Расстрелы и реквизиции, без которых невозможно было, по словам Н. Бухарина, воспитать нового человека, органично вписывались в Гражданскую войну и одновременно провоцировали ее. Это подтверждается тем фактом, что открытое недовольство политикой советского правительства и массовые восстания заметно активизировались после разгрома основных белых армий в 1920 г., что и привело впоследствии к отказу от политики военного коммунизма и переходу к нэпу.

Поначалу Россия не хотела участвовать в Гражданской войне, и потребовались месяцы террора, включая уничтожение царской семьи, массовые расстрелы заложников и т.п., для того чтобы привычка убивать, выработанная на фронте, переросла в массовое озверение, описанное не только в материалах следственных комиссий и трудах историков, но и в художественной литературе ${ }^{2}$. Потери населения на территории, оставшейся в границах советской России, оцениваются более чем в 12 млн чел., т.е. без малого 9\% населения, из которых половина умерли от голода и болезней, 2,5 млн эмигрировали, и более 2 млн стали жертвами террора. Гражданские войны носят характер религиозных и отличаются большей жестокостью в отношении противника и мирного населения. Революции и гражданские войны обязательно вызывают массовую эмиграцию, затрагивающую высшие слои общества, как правило, более образованные и активные. Например, после американской революции до 10\% населения (так называемые лоялисты) переселились в Канаду, то же произошло после английской или французской революций.

Наивно было бы предполагать, что террор прекратился после окончания войны. Расказачивание перешло в раскулачивание, которое сменилось политическими процессами, плавно перешедшими в так называемый «большой террор», и так до смерти И.В. Сталина. После этого террор стал уже индивидуальным, чего многие до сих пор не могут простить последующим правителям. И, как и в годы Гражданской войны, убыль населения и деградация человеческого капитала перед Второй мировой войной определялись не только и не столько физическим уничтожением, сколько голодом и болезнями, которые стали средством воспитания нового человека.

${ }^{2}$ Настоятельно рекомендую, помимо прочих, прочитать роман Артема Веселого «Россия, кровью умытая», написанный на основе воспоминаний участников событий (М.: Современник, 1989.- 508 с.). 
Одновременно с ликвидацией рыночных институтов, включая частную собственность, уничтожением имущих классов и максимальным упрощением социальной структуры общества советское правительство приступило к внешней экспансии. Мировая революция требовала дополнительной мобилизации внутренних ресурсов и использования их вне страны. Политика послереволюционной экспансии неоднократно встречалась в истории, начиная с английской и французской революций до китайской и иранской в новейшее время.

Но в случае России курс на мировую революцию был провозглашен изначально и к его реализации приступили незамедлительно еще до провозглашения Коминтерна в 1919 г. В эту политику укладывались и поддержка коммунистических и национально-освободительных движений, и прямое участие в конфликтах по всему миру, подготовка и участие СССР во Второй мировой войне, и политика противостояния двух систем в период «мирного сосуществования», и многое другое.

Участие СССР во Второй мировой войне привело к тяжелым потерям и невиданной убыли населения, которые связаны, в том числе, с многочисленными просчетами политики советского правительства в довоенный период. Историки до сих пор спорят о масштабах людских потерь СССР в годы Великой Отечественной войны, и оценки находятся в диапазоне от 25 до более 40 млн чел., в зависимости от методики подсчета и демографических потерь. Кроме того, СССР потерял в годы войны до 30\% национального богатства. Сравнение с потерями в Первой мировой войне, когда руководство страны и армии обвиняли в некомпетентности, а то и в прямом предательстве, приводит к неутешительным для советской системы выводам.

\section{Неравенство}

Как и многие иные, российская революция шла под лозунгами восстановления справедливости, борьбы за свободу, равенство и братство. Историко-экономические исследования фиксируют огромное имущественное расслоение и высокую дифференциацию доходов в дореволюционной России. Национализация и экспроприация, нормирование потребления, перераспределение жилого фонда в пользу городской бедноты после революции, казалось, должны были резко снизить имущественное неравенство и дифференциацию доходов. И статистика вроде бы это подтверждает. Проблема видится в том, что в условиях развала системы денежного обращения, нормирования распределения и прямого продуктообмена все эти расчеты превращаются в фикцию. И. Эренбург иронично писал: «Чем эта шикарная лестница пайков, от восьмушки хлеба до бутербродов с икрой, хуже шестнадцати классов нашего несчастного друга?»³. Вообще в системе, в которой отношения собственности по владению, распоряжению и использованию разделены, а цены устанавливаются директивно, исходя из политических и иных целей, говорить о распределении богатства и доходов в общепринятом смысле достаточно бессмысленно. Нэп не столько создавал имущественное расслоение, сколько переводил его из латентной в явную форму. На протяжении всего периода существования СССР дифференциация денежных доходов слабо отражала реальные различия в уровне и качестве жизни разных групп населения.

С середины 1950-х годов отношения владения, распоряжения и использования постепенно начинают сближаться. Причин тому множество: от роста защищенности номенклатуры и изменений в кадровой политике до экономических реформ и деградации плановой системы. Интересно, что одним из главных требований общественных движений периода перестройки и гласности стала борьба с привилегиями. Другими словами, в общественном мнении сформировалось представление не только о высокой дифференциации реальных доходов, но и о несправедливости такой системы.

Расчеты, проведенные на основании имеющихся данных, показывают, что доля доходов верхних 1\% и 10\% населения России действительно резко сократилась с 18\% и 47\% в 1905 г. до менее 4\% и 23\% в 1925 г., но потом выросла до 6\% и 26\% к 1955 г. [4]

Некоторое снижение дифференциации доходов в 19551985 гг. можно объяснить как ростом среднего класса, так и постепенным нарастанием дефицита потребительских товаров и развитием теневого сектора, что делает оценки менее

${ }^{3}$ Имеется в виду один из героев романа, месье Дэле, прейскурант которого на похоронные услуги включал 16 классов, в зависимости от цены [3. С. 175]. 
надежными. Но взрывной рост неравенства в доходах после 1985 г. представляется вполне адекватным. В результате 1\% наиболее богатого населения страны в 2015 г. располагал 20\% доходов, а верхние 10\% получили 47\% всех доходов. Это несколько меньше, чем в предкризисном 2005 г., но выше, чем в дореволюционной России [4]. Высокая дифференциация доходов, помимо ощущения несправедливости, создает барьеры для экономического роста и социальной мобильности.

Следует отметить, что общественное восприятие дифференциации доходов зависит, по крайней мере, от двух факторов. Во-первых, с ним тем легче мириться, чем богаче страна. Поскольку средние доходы в современной России несколько выше, чем во времена СССР и, тем более, в дореволюционной России, то неприятие существующего положения ограничивается в основном словесной критикой. Во-вторых, отношение к высокой дифференциации и низкому уровню доходов у большинства населения тем мягче, чем выше социальная и профессиональная мобильность. Это объясняет, почему в довоенное время и в 1990-е гг. сохранялась относительная стабильность в обществе, несмотря на резкое падение доходов у большей части населения. Высокая социальная мобильность в 1930-е гг. и в послевоенное время, вызванная главным образом массовыми репрессиями, до сих пор является предметом гордости сторонников советской власти, равно как и стабильность в период экстенсивного роста в последующие годы.

Разумеется, большой вклад в поддержание социальной стабильности, помимо роста доходов и снижения их дифференциации, вносят репрессии, идеологическая обработка населения, демонстрация отдельных успехов, мобилизация в борьбе с внешними и внутренними врагами и многое другое, но условия жизни, перспективы их улучшения и сравнение собственного положения с положением других играют очень важную роль. Смешение в памяти периодов высокой социальной мобильности и социальной стабильности является основным источником ностальгии по советской эпохе. Советские люди были чем-то похожи на персонажей Льюиса Кэрролла из «Алисы в Зазеркалье», которые хорошо знали будущее, путались в настоящем и ничего не знали о прошлом.

\section{Опыт альтернативной истории}

Многие экономисты увлекаются историей. Это неудивительно, поскольку они работают со статистикой, которая отражает то, что уже произошло. Кроме того, они пытаются выявить причинно-следственные связи и объяснить события и их последствия. Наконец, экономисты пытаются понять общество, в котором они живут, и объяснить тенденции его развития.

Разумеется, история в той мере, в которой она остается наукой, не терпит сослагательного наклонения. Но продолжающиеся идеологические споры вокруг истории нашей страны, в частности вокруг революционных событий вековой давности, делают неизбежным обсуждение их социально-экономических последствий. Следует сразу оговориться, что дискуссия о революции и ее последствиях носит идеологический характер, и истина в ней родиться не может.

Экономисты оценивают события, решения и отдельные проекты двумя способами. Если проекты в сопоставлении невелики, то можно сравнивать затраты и выгоды. Если же мы имеем дело с масштабными проектами, меняющими структуру экономики и общества, то используется модель, описывающая систему в целом, и проводятся вариантные расчеты (с проектом и без него). События в России в 1917 г. имели всемирно-историческое значение и не могут быть отнесены к разряду малых.

Экономическая история дореволюционной России достаточно хорошо описана, и хотя выводы из многочисленных работ различны, статистическая база для исследований сформирована [5]. Кроме того, изучена экономическая история СССР и, в определенной степени, проведены корректировка статистической информации и ее очистка от приписок и искажений [6].

Несмотря на продолжающуюся дискуссию о действительных достижениях СССР в области экономики, можно считать доказанным, что публиковавшиеся данные ЦСУ были существенно завышены. Более того, это относится и к оценкам зарубежных авторов, профессионально изучавших экономику СССР. Напрашивается пример с ГДР, экономика которой оказалась много слабее, чем представлялось до объединения.

Но это не единственные трудности для сопоставления ретропрогноза с фактическим развитием страны. Представляются некорректными как прямая экстраполяция на столетний период, 
так и использование аппарата производственных функций, поскольку показатели эластичности факторов должны меняться в больших пределах. Остаются качественные оценки на основе сопоставления с развитием других стран с учетом влияния ключевых событий XX века.

Во-первых, выделим неизбежный процесс деколонизации и распада империй. Вероятно, в иных условиях он протекал бы медленнее и менее драматично. Возможны и иные сценарии. Но, несомненно, этот процесс затронул бы и Россию. Не исключено, что некоторые части империи, такие, как Польша, стали бы независимыми, а на части территории Сибири и Дальнего Востока сформировалось бы нечто, напоминающее доминионы Британской империи.

Во-вторых, Россия, несомненно, участвовала бы в многочисленных войнах, которыми был так богат XX век. Потери в них были бы не столь грандиозны, как в Великой Отечественной войне, но все же очень серьезны.

В-третьих, Великая депрессия и другие экономические кризисы обязательно затронули бы Россию, интегрированную в мировое хозяйство.

Наконец, Россия в XX веке пережила бы начавшийся в XIX веке демографический переход, урбанизацию и смену модели развития. Экстенсивный рост сменился бы на интенсивный. Остается открытым вопрос о преобладающем направлении внешней миграции: осталась бы Россия нетто-экспортером населения и трудовых ресурсов или наоборот?

Но несомненно, что Россия не потеряла бы большую часть своего научно-технического и образовательного потенциала в годы Гражданской войны и последующих десятилетий репрессий, сельскохозяйственного - в период коллективизации и индустриализации, и промышленного - в годы войны. Значительная часть периода экономического развития после революции 1917 г. приходится на восстановительный рост, чем во многом и определялись его высокие темпы в отдельные годы ${ }^{4}$. Но за столетие темпы роста будут весьма невелики, поскольку сначала создавались

${ }^{4}$ Другими причинами высоких темпов экономического роста в период индустриализации являются милитаризация экономики и диспаритет цен. Но милитаризация экономики имеет преимущественно краткосрочный положительный эффект и в долгосрочном периоде наносит ущерб экономическому развитию. проблемы, а потом они преодолевались. Периоды максимальной мобилизации всех ресурсов сменялись периодами релаксации.

Скорее всего, численность населения России в нынешних границах была бы примерно в 1,5-2 раза больше, уровень урбанизации - несколько ниже, дифференциация доходов и имущества - много выше, чем в советское время, но ниже современной. Межрегиональные диспропорции были бы ниже, чем в настоящее время, а доля промышленности в экономике - несколько выше нынешней, хотя и ниже, чем в советское время. Удельные показатели ВВП и доходов населения примерно вдвое превышали бы существующие в настоящий момент.

Собственно, более подробно обсуждать результаты российской революции нет необходимости, поскольку эксперимент, начатый 100 лет назад и продолжавшийся 3/4 века, завершился провалом. Поэтому так легко он был закончен. Но переход к новой социально-экономической системе обошелся России необычайно дорого.

\section{Заключение}

Революции, т.е. быстрое изменение политико-экономических основ общественного устройства и развития, неизбежны, как неустранимы противоречия и конфликты в любом обществе, имеющие не только материальную, но и ценностную основу. Главная проблема - что происходит после революции. Если, в терминах К. Маркса, общество сбрасывает кандалы старых производственных отношений и открывает возможности для развития производительных сил, или, согласно Д. Норту и другим авторам, позволяет формировать социальный порядок с открытым доступом, то издержки революции более чем компенсируются резким ускорением экономического роста и развития в долгосрочной перспективе. В терминах Д. Аджемоглу и Дж. Робинсона, это инклюзивные институты. Но если в результате революции формируются и, главное, набирают силу институты, препятствующие конкуренции, и получают развитие экстрактные институты, созданные для извлечения ресурсов у многих немногими и неспособные защищать права собственности или создавать стимулы для экономической деятельности, то такое общество обречено на отставание и деградацию в меняющемся мире. 
Русская революция действительно устранила многие сословные и национальные барьеры. Но, с другой стороны, лишив имущие классы прав и собственности самым варварским способом, подвергнув их репрессиям, она способствовала снижению конкуренции. Параллельно шло формирование номенклатуры и превращение ее в относительно замкнутую касту, ориентированную на извлечение ренты. Революция начала 1990-х гг. также устранила многие барьеры, но потом были воссозданы новые. Тем самым завершился круг российской истории за последнее столетие.

\section{Литература}

1. Клисторин В. И. Россия в 1913 году // ЭКО.- 2013.- № 12.- С. 5-18. 2. Клисторин В.И. Россия в 1915 году //ЭКО.- 2015.- № 4.- С. 152-160. 3. Эренбург И.Г. Необычайные похождения Хулио Хуренито и его учеников. Собр. соч. в девяти томах, Т. 1. - М.: Гос. изд-во худ. литературы, 1962.- 534 с.

4. Novokmet F, Piketty T., Zucman G. From soviets to oligarchs: Inequality and property in Russia, 1905-2016. National bureau of economic research, Cambridge.- MA, USA, 02138.- 2017.- Aug. URL: http://www.nber.org/ papers/w23712

5. Грегори П. Экономический рост Российской империи (конец XIX начало XXв.). Новые подсчеты и оценки.- М.: Российская политическая энциклопедия (РОССПЭН), 2003.- 256 с.

6. Ханин Г.И. Экономическая история России в новейшее время / Учеб. пособие в 3 ч.- Новосибирск: Изд. СибАГС, 2003-2011 гг. См. также и другие работы этого автора. 